\title{
Effect of chromium on bioenergetics and leukocyte dynamics following immunoactivation in lactating Holstein cows
}

\author{
E. A. Horst, ${ }^{*}$ S. K. Kvidera, ${ }^{*}$ E. J. Mayorga, ${ }^{*}$ C. S. Shouse, ${ }^{*}$ M. Al-Qaisi, ${ }^{*}$ M. J. Dickson, ${ }^{*}$ J. Ydstie, ${ }^{*}$ \\ H. A. Ramirez Ramirez, ${ }^{*}$ A. F. Keating, ${ }^{*}$ D. J. Dickson,† K. E. Griswold,† and L. H. Baumgard*1 \\ *Department of Animal Sciences, lowa State University, Ames 50011 \\ †Kemin Industries, Des Moines, IA 50317
}

\begin{abstract}
Activated immune cells are insulin sensitive and utilize copious amounts of glucose. Because chromium (Cr) increases insulin sensitivity and may be immunomodulatory, our objective was to evaluate the effect of supplemental Cr (KemTrace Cr propionate, $20 \mathrm{~g} / \mathrm{d}$; Kemin Industries Inc., Des Moines, IA) on immune system glucose utilization and immune system dynamics following an intravenous endotoxin challenge in lactating Holstein cows. Twenty cows $(320 \pm 18 \mathrm{~d}$ in milk) were randomly assigned to 1 of 4 treatments: (1) pairfed (PF) control (PF-CON; $5 \mathrm{~mL}$ of saline; $\mathrm{n}=5)$, (2) $\mathrm{PF}$ and $\mathrm{Cr}$ supplemented (PF-Cr; $5 \mathrm{~mL}$ of saline; $\mathrm{n}=$ 5), (3) lipopolysaccharide (LPS)-euglycemic clamp and control supplemented (LPS-CON; $0.375 \mu \mathrm{g} / \mathrm{kg}$ of body weight LPS; $\mathrm{n}=5$ ), and (4) LPS-euglycemic clamp and Cr supplemented (LPS-Cr; $0.375 \mu \mathrm{g} / \mathrm{kg}$ of body weight LPS; $\mathrm{n}=5)$. The experiment was conducted serially in 3 periods $(\mathrm{P})$. During P1 (3 d), cows received their respective dietary treatments and baseline values were obtained. At the initiation of P2 (2 d), either a 12-h LPS-euglycemic clamp was conducted or cows were PF to their respective dietary counterparts. During P3 $(3 \mathrm{~d})$, cows consumed feed ad libitum and continued to receive their respective dietary treatment. During P2, LPS administration decreased dry matter intake (DMI; 40\%) similarly among diets, and by experimental design the pattern and magnitude of reduced DMI were similar in the PF cohorts. During P3, LPS-Cr cows tended to have decreased DMI $(6 \%)$ relative to LPS-CON cows. Relative to controls, milk yield from LPS-challenged cows decreased (58\%) during P2 and LPS-Cr cows produced less (16\%) milk than LPS-CON cows. During P3, milk yield progressively increased similarly in LPS-administered cows, but overall milk yield remained decreased (24\%) compared with $\mathrm{PF}$
\end{abstract}

Received September 25, 2017

Accepted February 5, 2018.

${ }^{1}$ Corresponding author: baumgard@iastate.edu controls. There were no dietary treatment differences in milk yield during P3. Circulating insulin increased 9- and 15-fold in LPS-administered cows at 6 and 12 h postbolus, respectively, compared with PF controls. Compared with LPS-CON cows, circulating insulin in LPS-Cr cows was decreased (48\%) at $6 \mathrm{~h}$ postbolus. Relative to PF cows, circulating LPS binding protein and serum amyloid A from LPS-administered cows increased 2- and 5-fold, respectively. Compared with PF cows, blood neutrophil counts in LPS-infused cows initially decreased, then gradually increased $163 \%$. Between 18 and $48 \mathrm{~h}$ postbolus, the number of neutrophils was increased (12\%) in LPS-Cr versus LPS-CON cows. The 12-h total glucose deficit was 220 and $1,777 \mathrm{~g}$ for the PF and LPS treatments, respectively, but glucose utilization following immune activation was not influenced by Cr. In summary, supplemental $\mathrm{Cr}$ reduced the insulin response and increased circulating neutrophils following an LPS challenge but did not appear to alter the immune system's glucose requirement following acute and intense activation.

Key words: chromium, lipopolysaccharide, insulin, neutrophil

\section{INTRODUCTION}

Dairy cows employ homeorhetic mechanisms to support dominant physiological states (i.e., growth, reproduction, lactation; Bauman and Currie, 1980), and during lactation this is in large part characterized by decreased circulating insulin coupled with reduced insulin sensitivity in adipose tissue and skeletal muscle (De Koster and Opsomer, 2013; Baumgard et al., 2017). However, immunoactivation markedly reprioritizes the hierarchy of coordinated nutrient trafficking (Bradford et al., 2015) at the expense of milk synthesis. Inflammation is caused by multiple pathologies, including mastitis, metritis, heat stress, intestinal barrier dysfunction, and feed restriction (Lambert et al., 2002; Sheldon et al., 2008; Ballou, 2012; Zhang et al., 2013; Kvidera et al., 2017a,d). Although these insults have 
differing etiologies, inflammation and suboptimal production are common outcomes; therefore, identifying strategies amenable to dietary manipulation that could facilitate the immune response or ameliorate production loses during immunoactivation would largely affect animal health and farm profitability.

Upon activation, immune cells become obligate glucose utilizers and shift ATP production from oxidative phosphorylation to aerobic glycolysis, a process known as the "Warburg effect" (Palsson-McDermott and O'Neill, 2013). During an immune challenge circulating insulin increases, likely because insulin facilitates immune cell glucose uptake and improves function (Walrand et al., 2004). In an attempt to spare glucose for the immune system, muscle and adipose tissue become insulin resistant (Lang et al., 1990) and milk synthesis is reduced (Kvidera et al., 2017b). However, the ubiquitous nature of leukocytes makes quantifying the immune system's in vivo glucose consumption difficult. By using an LPS-euglycemic clamp technique, we recently demonstrated that an activated immune system utilizes $>1 \mathrm{~kg}$ of glucose within $12 \mathrm{~h}$ in the lactating cow model (Kvidera et al., 2017b). Thus, mounting an immune response is energetically expensive, and strategies that divert glucose toward activated leukocytes may allow for a more efficient immune response.

Chromium $(\mathrm{Cr})$ potentiates insulin action (Chen et al., 2006), and although the exact mechanism is not fully understood, it appears to work intimately with chromodulin (or low-molecular-weight Cr-binding substance; Vincent, 2015). In response to insulin, Cr enters insulin-sensitive cells and, in combination with chromodulin, binds to the insulin receptor, which amplifies downstream signaling cascades (Vincent, 2015). Subsequently, GLUT-4 translocation to the plasma membrane is improved and glucose uptake is increased (Chen et al., 2006), a potential benefit to insulin-sensitive immune cells upon activation. Therefore, study objectives were to evaluate effects of supplemental $\mathrm{Cr}$ on glucose consumption and circulating leukocyte dynamics in an acute and intensely activated immune system via the LPS-euglycemic clamp technique.

\section{MATERIALS AND METHODS}

\section{Animals and Experimental Design}

All procedures were approved by the Iowa State University Institutional Animal Care and Use Committee. Twenty nonpregnant lactating Holstein cows $(781 \pm 21$ $\mathrm{kg}$ of BW; $320 \pm 18$ DIM; parity $3 \pm 0.3$ ) were used in an experiment conducted in 2 replications (10 cows/replicate). Cows were housed in individual boxstalls $(4.57 \times$ $4.57 \mathrm{~m}$ ) at the Iowa State University Dairy Farm. Cows were allowed $4 \mathrm{~d}$ to acclimate to housing and feeding conditions; during this time, they were implanted with bilateral jugular catheters. Beginning on d 1 of acclimation and through study completion, cows received 1 of 2 dietary treatments: (1) a control supplement $(20 \mathrm{~g} / \mathrm{d}$ of calcium carbonate) or (2) a Cr supplement (KemTrace Cr propionate, $20 \mathrm{~g} / \mathrm{d}$ to deliver $8 \mathrm{mg}$ of $\mathrm{Cr} / \mathrm{d}$; Kemin Industries Inc., Des Moines, IA). Supplements were provided as a top-dress premixed with ground corn at a rate of $200 \mathrm{~g} / \mathrm{d}$. Period 1 (P1) lasted $3 \mathrm{~d}$ and served as the baseline (data generated for covariate analysis) for periods 2 (P2) and 3 (P3). At the initiation of $\mathrm{P} 2$, which lasted $48 \mathrm{~h}$, animals either experienced a 12-h LPS-euglycemic clamp as previously described (Kvidera et al., 2017b) or were pair fed (PF) to their respective dietary counterparts for the entire $48 \mathrm{~h}$ to eliminate the confounding effects of dissimilar nutrient intake. Dietary and challenge combinations resulted in 4 treatments: (1) PF and control supplemented (PFCON; $5 \mathrm{~mL}$ of sterile saline with control supplement; $\mathrm{n}=5)$, (2) PF and Cr supplemented (PF-Cr; $5 \mathrm{~mL}$ of sterile saline with $\mathrm{Cr}$ propionate supplement; $\mathrm{n}=5$ ), (3) LPS-euglycemic clamp and control supplemented (LPS-CON; $0.375 \mu \mathrm{g} / \mathrm{kg}$ of BW LPS with control supplement; $\mathrm{n}=5$ ), and (4) LPS-euglycemic clamp and Cr supplemented (LPS-Cr; $0.375 \mu \mathrm{g} / \mathrm{kg}$ of BW LPS with $\mathrm{Cr}$ propionate supplement; $\mathrm{n}=5$ ). Period 3 lasted $3 \mathrm{~d}$, during which all animals continued to receive their dietary treatment but were allowed to consume feed ad libitum.

All cows were fed a diet formulated to meet or exceed the predicted requirements (NRC, 2001; Table 1) of energy, protein, minerals, and vitamins. Reduced feed intake in LPS-treated cows during P2 was determined as a percentage of their mean daily ad libitum intake during P1. Throughout the experiment, PF cows lagged $1 \mathrm{~d}$ behind LPS-infused cows to allow for pair-feeding calculations as previously described (Baumgard et al., 2011).

Cows were milked 4 times daily $(0000,0600,1200$, and $1800 \mathrm{~h}$ ) during P1 and P2 and twice daily (0600 and $1800 \mathrm{~h}$ ) during P3. Milk yield was recorded, and a sample for composition analysis was obtained at each milking. Samples were stored at $4^{\circ} \mathrm{C}$ with a preservative (bronopol tablet; D \& F Control System, San Ramon, CA) until analysis by Dairy Lab Services (Dubuque, IA) using infrared analysis equipment and procedures approved by AOAC International (1995). Rectal temperature $(\mathbf{T r})$, respiration rate $(\mathbf{R R})$, and heart rate (HR) were recorded after each milking. Heart rate and $\mathrm{RR}$ were measured as beats or flank movements during a 15-s interval and later transformed to beats per minute and breaths per minute, respectively. Rectal temperature was measured using a digital thermometer 
(GLA M700 digital thermometer, San Luis Obispo, $\mathrm{CA})$.

To estimate the glucose requirements of an activated immune system, we used the LPS-euglycemic clamp technique as recently described (Kvidera et al., 2016, 2017b). Selecting the LPS dose was influenced by the magnitude of hypoglycemia observed in earlier reports and expected to cause a 40 to $50 \%$ decrease in milk production (Giri et al., 1990; Waldron et al., 2003b; Waggoner et al., 2009; Kvidera et al., 2017b). Lipopolysaccharide (Escherichia coli O55:B5; Sigma-Aldrich, St. Louis, MO) was dissolved in sterile saline at a concentration of $500 \mu \mathrm{g} / \mathrm{mL}$ and passed through a $0.2-$ $\mu \mathrm{m}$ sterile syringe filter (Thermo Scientific, Waltham, MA). The total volume of LPS solution administered was approximately $4 \mathrm{~mL}$. Maintaining the euglycemic clamp involved intravenously infusing $50 \%$ glucose (as dextrose; VetOne, Boise, ID) at a known and adjustable rate using a modular pump (Deltec 3000, Deltec Inc., St. Paul, MN) to maintain the pre-LPS administration blood glucose concentrations.

Catheters were inserted into both jugular veins in all cows before P1 as previously described (Baumgard et al., 2011). Blood samples were obtained at -30 , -20 , and 0 min relative to LPS or saline bolus administration to establish baseline glucose levels. Each respective treatment bolus was administered immediately following the 0-min blood sample collection. For cows receiving LPS, postbolus blood samples $(1 \mathrm{~mL})$

Table 1. Ingredients and composition of $\operatorname{diet}^{1}(\%$ of DM unless noted)

\begin{tabular}{lc}
\hline Item & Value $^{2}$ \\
\hline Ingredient & \\
Corn silage & 33.6 \\
Corn gluten feed & 19.1 \\
Alfalfa hay & 15.8 \\
Lactation grain & 11.7 \\
Ground corn & 8.2 \\
Whole cottonseed & 4.8 \\
Molasses & 2.8 \\
Expeller soybean meal & 2.4 \\
Soybean meal & 1.7 \\
Chemical analysis & \\
Starch & 20.7 \\
CP & 19.2 \\
NDF & 34.8 \\
ADF & 21.5 \\
Fat & 4.98 \\
NE & Mcal/kg of DM) \\
\hline
\end{tabular}

${ }^{1}$ Values represent an average of ration nutrient summary reports collected throughout the trial. Diet moisture averaged $52.49 \%$.

${ }^{2}$ Average nutrient levels: $0.99 \% \mathrm{Ca}, 0.53 \% \mathrm{P}, 0.39 \% \mathrm{Mg}, 0.25 \% \mathrm{~S}$, $1.42 \% \mathrm{~K}, 0.51 \% \mathrm{Na}, 0.55 \% \mathrm{Cl}, 68.25 \mathrm{mg} / \mathrm{kg}$ of Zn, $45.66 \mathrm{mg} / \mathrm{kg}$ of Mn, $3.62 \mathrm{mg} / \mathrm{kg}$ of $\mathrm{Fe}, 13.92 \mathrm{mg} / \mathrm{kg}$ of Cu, $0.78 \mathrm{mg} / \mathrm{kg}$ of Co, $0.33 \mathrm{mg} / \mathrm{kg}$ of Se, $0.78 \mathrm{mg} / \mathrm{kg}$ of I, $6,645.2 \mathrm{IU} / \mathrm{kg}$ of vitamin A, $572.9 \mathrm{IU} / \mathrm{kg}$ of vitamin $\mathrm{D}$, and $18.4 \mathrm{IU} / \mathrm{kg}$ of vitamin $\mathrm{E}$. were collected every $10 \mathrm{~min}$ and immediately analyzed for glucose concentration (Truebalance glucometer; McKesson, San Francisco, CA). Glucose infusion began when blood glucose content decreased below baseline levels, and its rate of infusion was adjusted as necessary to maintain euglycemia $( \pm 5 \%)$. The rate of $50 \%$ glucose infusion $(\mathrm{mL} / \mathrm{h})$ was transformed to rate of glucose infusion (ROGI; g/h). The total glucose infused for each cow was calculated using the ROGI for each 10-min interval (72 intervals total) according to the following equation:

$$
\sum_{i=0}^{72} \operatorname{ROGI}(\mathrm{g} / \mathrm{h})_{i} \times \frac{1 \mathrm{~h}}{60 \min } \times 10 \min .
$$

Blood glucose was measured every $3 \mathrm{~h}$ in PF cows. Vital measurements ( $\mathrm{Tr}, \mathrm{RR}$, and $\mathrm{HR}$ ) were obtained at -0.5 and $0 \mathrm{~h}$ relative to LPS administration, every 3 $\mathrm{h}$ for the first $12 \mathrm{~h}$ postbolus, and every $6 \mathrm{~h}$ thereafter.

Blood samples were collected daily at $1800 \mathrm{~h}$ during P1 from the catheter and divided equally between a tube containing $\mathrm{K}_{2}$ EDTA (BD, Franklin Lakes, NJ; for plasma collection) and an empty glass tube (for serum collection). Additional plasma and serum samples ( $\sim 10$ $\mathrm{mL}$ each) were collected from all treatments at -0.5 , $-0.33,0,3,6,9,12,18,24,30,36,42$, and 48 h relative to bolus administration during P2. Serum samples were allowed to clot at room temperature for $1 \mathrm{~h}$ before centrifugation. Plasma and serum were harvested following centrifugation at $1,500 \times g$ for $15 \mathrm{~min}$ at $4^{\circ} \mathrm{C}$ and were subsequently frozen at $-20^{\circ} \mathrm{C}$ until analysis.

Plasma insulin, nonesterified fatty acids (NEFA), BHB, LPS binding protein (LBP), serum amyloid A (SAA), haptoglobin (Hp), BUN, and glucose concentrations were determined using commercially available kits according to the manufacturers' instructions (insulin: Mercodia AB, Uppsala, Sweden; NEFA: Wako Chemicals USA, Richmond, VA; BHB: Pointe Scientific Inc., Canton, MI; LBP: Biomedical Research Service Center, Buffalo, NY; SAA: Tridelta Development Ltd., Kildare, Ireland; Hp: Immunology Consultants Laboratory Inc., Portland, OR; BUN: Teco Diagnostics, Anaheim, CA; glucose: Wako Chemicals USA). The inter- and intra-assay coefficients of variation for glucose, insulin, NEFA, BHB, SAA, LBP, and BUN assays were 7.2 and $4.1 \%, 7.1$ and $5.6 \%, 4.0$ and $3.2 \%, 6.9$ and $6.2 \%, 20.5$ and $11.8 \%, 12.3$ and $3.9 \%$, and 6.2 and $4.6 \%$, respectively, and the intra-assay coefficient of variation for Hp was $7.8 \%$.

Samples for complete blood count analysis were collected at $-30 \mathrm{~min},-20 \mathrm{~min}$, and $0,3,6,9,12,18,24$, $30,36,42$, and $48 \mathrm{~h}$ relative to bolus administration. A 3-mL blood sample was collected from the catheter 
$\left(\mathrm{K}_{2}\right.$ EDTA; BD) and stored at $4^{\circ} \mathrm{C}$ for approximately $12 \mathrm{~h}$ before being submitted to the Iowa State University's Department of Veterinary Pathology for analysis. Samples for iSTAT analysis were measured using an iSTAT hand-held machine and cartridge (CG8+; Abbott Point of Care, Princeton, NJ) and were obtained at $0,12,24$, and $48 \mathrm{~h}$ relative to bolus administration.

\section{Calculations and Statistical Analyses}

Administering LPS reduces milk yield and therefore decreases glucose utilized for milk synthesis. The decrease in milk yield allowed us to estimate the amount of glucose conserved (milk glucose deficit) due to reduced feed intake alone (PF-CON and PF-Cr cows) and decreased feed intake coupled with ostensible glucose utilization by the immune system (LPS-CON and LPS-Cr cows). The amount of glucose utilized for milk synthesis was calculated for each milking based on Kronfeld's (1982) estimation of $72 \mathrm{~g}$ of glucose required to synthesize $1 \mathrm{~kg}$ of milk. Milk glucose output before the challenge was averaged to establish a baseline. Milk glucose utilization at both 6 and $12 \mathrm{~h}$ was subtracted from the baseline to calculate the milk glucose deficit. For PF-CON and PF-Cr cows, milk glucose deficit was used solely to calculate total glucose deficit. For LPSCON and LPS-Cr cows, milk glucose deficit plus the amount of glucose infused to maintain euglycemia were combined to obtain the total glucose deficit. After cessation of the euglycemic clamp (12 h postbolus), milk glucose deficit continued to be calculated every $6 \mathrm{~h}$ until $48 \mathrm{~h}$ postbolus.

Each animal's respective response variable was analyzed using repeated measures with an autoregressive covariance structure for feed intake and iSTAT parameters and spatial power law structure for vitals, milk yield, milk composition, complete blood cell count, and blood metabolites. The repeated effect was time relative to bolus administration. There were no treatment differences in any measured variable during P1; thus, each specific variable's prebolus values (i.e., P1 average, when available) served as a covariate for analysis of P2 and P3 (each period was statistically analyzed separately). Effects of treatment, time (hours relative to bolus), treatment $\times$ time interaction, and replicate were assessed as a completely randomized design using PROC MIXED (SAS Institute Inc., Cary, NC). Preformed contrasts were used to estimate differences between control and Cr-supplemented cows, PF and LPS-administered cows, and LPS-CON and LPS-Cr cows. Data are reported as least squares means and considered significant if $P \leq 0.05$ and a tendency if 0.05 $<P \leq 0.10$.

\section{RESULTS}

During P2 and irrespective of Cr, LPS-administered cows had mild hyperthermia $\left(+0.82^{\circ} \mathrm{C}\right)$ between 3 and $6 \mathrm{~h}$ postbolus relative to PF cows, whose Tr remained unchanged $(P<0.01 ;$ Figure $1 \mathrm{~A})$. Respiration rate was decreased 5 breaths/min, whereas HR was increased 8 beats/min in LPS cows relative to PF cows $(P<0.01$; data not shown). Heart rate of LPS-Cr cows tended to be increased ( 4 beats $/ \mathrm{min}$ ) compared with LPS-CON cows $(P=0.07$; data not shown). Period 3 HR of LPS cows was increased 4 beats/min relative to their $\mathrm{PF}$ counterparts $(P=0.04$; data not shown), but $\operatorname{Tr}$ and $\mathrm{RR}$ did not differ between treatments.

Lipopolysaccharide administration decreased DMI (40\%) relative to baseline during $\mathrm{P} 2$, and the pattern and extent of reduced DMI were similar for cows in the $\mathrm{PF}$ treatments by experimental design $(P=0.36$; Figure 1B). Feed intake increased similarly $(115 \%)$ from P2 d1 to P2 d2 postbolus for all treatments $(P<0.01)$. Relative to PF cows, DMI of LPS-administered cows remained decreased during P3 (13\%; $P<0.01$; Figure 1B). Chromium supplementation tended to decrease DMI $(6 \%)$ relative to the control treatment during P3 $(P=0.10$; Figure 1B). Relative to PF controls, milk yield from LPS-administered cows was decreased (58\%) during P2 $(P<0.01$; Figure $1 \mathrm{C})$, and P2 d1 and P2 d2 milk yields were decreased 66 and $49 \%$, respectively $(P \leq 0.01$; Figure 1C). Chromium-supplemented cows produced less milk $(16 \%)$ than control cows throughout the 8 milkings during P2 $(P=0.05$; Figure $1 \mathrm{C})$. The milk yield nadir of LPS treatments occurred $6 \mathrm{~h}$ postbolus and was decreased $86 \%$ relative to the baseline value $(P<0.01)$. By the end of $\mathrm{P} 2$, milk yield from LPS-administered cows increased relative to P2 d1 but remained $61 \%$ decreased compared with baseline $(P<$ $0.01)$. After $12 \mathrm{~h}$ of pair feeding, milk yield from PFCr cows decreased $40 \%$ relative to baseline values ( $P$ $=0.03)$; milk yield from PF-CON cows did not differ from baseline $(P=0.11)$ but was numerically decreased (26\%). During the LPS-euglycemic clamp, maintaining euglycemia via exogenous glucose infusion did not rescue milk yield as LPS-euglycemic cows had a $74 \%$ decrease in milk yield relative to PF cows. During P3, there was a tendency for a treatment $\times$ time interaction where control cows' milk yield remained unchanged, whereas LPS cows gradually approached the yield of the PF cows $(P=0.06$; Figure $1 \mathrm{C})$. Overall, during P3, daily milk yield of LPS-administered cows remained decreased $(24 \%)$ relative to PF cows $(P<0.01$; Figure $1 \mathrm{C})$. No effect of diet on milk yield was observed during P3.

Relative to PF cows, milk lactose content from LPS-infused cows decreased (15\%; $P<0.01$; Table 2), 
whereas milk fat content increased $(35 \% ; P<0.01$; Table 2). Milk protein content of LPS-treated cows increased relative to that of PF cows $(21 \% ; P<0.01$; Table 2). There was a treatment $\times$ time interaction $(P=0.04$; Table 2$)$ for MUN such that LPS-Cr cows experienced an increase between 18 and $42 \mathrm{~h}$ postbolus, whereas MUN from PF-Cr cows decreased. All treat- ments returned to baseline values by $48 \mathrm{~h}$ postbolus. Milk SCC from all treatments increased with time $(P=$ 0.05 ; Table 2). No treatment differences were observed in any milk component content during P3.

A period of hyperglycemia ( $\sim 180 \mathrm{~min})$ was observed post-LPS administration, after which continuous glucose infusion was necessary to maintain euglycemia $(P$
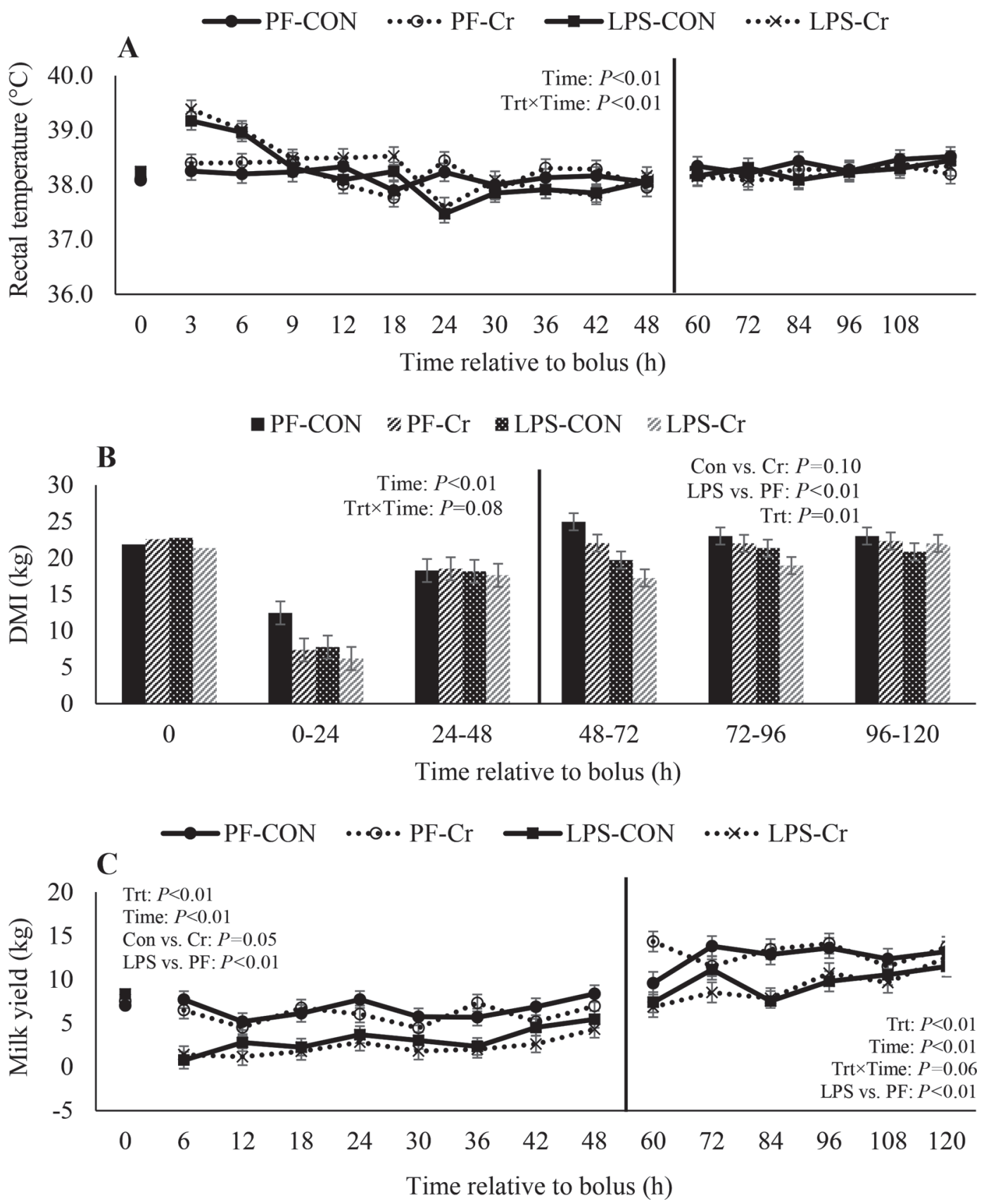

Figure 1. Effects of an LPS bolus or pair feeding in cows fed a control diet (CON) or a chromium (Cr) propionate-supplemented diet on (A) rectal temperature, (B) DMI, and (C) milk yield. The solid line separates period 2 from period 3 and represents 2 separate statistical models. PF-CON = pair-fed, saline bolus, control; PF-Cr = pair-fed, saline bolus, chromium; LPS-CON $=$ ad libitum, LPS bolus, control; LPS-Cr $=$ ad libitum, LPS bolus, chromium; Trt = treatment. Vertical bars represent SEM. 
$<0.01 ;$ Figure 2A). The ROGI increased with time $(P$ $<0.01$ ) but was not affected by diet (Figure 2A). The total mean glucose deficit accumulated over the $12 \mathrm{~h}$ was $120,319,1,772$, and $1,781 \mathrm{~g}$ for the PF-CON, PF$\mathrm{Cr}$, LPS-CON, and LPS-Cr treatments, respectively (Figure 2B). Chromium supplementation had no effect on the total glucose deficit. The 48-h milk glucose deficit was increased 4 -fold in LPS treatments relative to $\mathrm{PF}$ controls $(P<0.01$; data not shown). Interestingly, the milk glucose deficit of Cr-supplemented cows was numerically increased relative to CON-supplemented cows $(P=0.15)$.

Insulin concentrations were increased 9 - and 15-fold in LPS-administered cows at 6 and $12 \mathrm{~h}$, respectively, relative to $\mathrm{PF}$ cows $(P<0.01$; Figure $3 \mathrm{~A})$. Circulating insulin from LPS cows remained increased $(81 \%)$ between 18 and $48 \mathrm{~h}$ postbolus relative to PF cows $(P$ $=0.04)$. At $6 \mathrm{~h}$ postbolus, insulin concentrations from the LPS-Cr cows were decreased (48\%) relative to LPSCON cows $(P=0.02)$. Circulating NEFA in PF cows increased between 6 and $18 \mathrm{~h}$ postbolus, whereas NEFA from LPS treatments did not increase until $18 \mathrm{~h}$ postbolus. Circulating NEFA from cows in all treatments gradually declined between 18 and $48 \mathrm{~h}(P<0.01$; Figure $3 \mathrm{~B}$ ). Circulating BHB tended to be decreased in LPS versus PF treatments $(16 \% ; P=0.07$; Figure $3 \mathrm{C})$ and increased in all treatments with time $(P<0.01)$. Blood urea nitrogen concentrations increased in LPSadministered cows compared with PF cows $(31 \% ; P=$ 0.02 ; Figure $3 \mathrm{D}$ ). There was a tendency for a treatment $\times$ time interaction, such that BUN from LPS-Cr cows continued to increase between 24 and $36 \mathrm{~h}$ postbolus, whereas BUN in cows from all other treatments began to decrease $(P=0.08$; Figure 3D). Except insulin, $\mathrm{Cr}$ supplementation had no effect on the aforementioned circulating metabolites.

In LPS-administered cows, circulating LBP was increased relative to $\mathrm{PF}$ cows $(78 \% ; P<0.01$; Figure $4 \mathrm{~A}$ ), peaking at a $121 \%$ increase $24 \mathrm{~h}$ postbolus. Relative to $\mathrm{PF}$ cows, SAA concentrations were increased 5 -fold $(P<0.01$; Figure $4 \mathrm{~B})$ and continually increased over all time points measured $(P<0.01)$. There was a treatment $\times$ time interaction for Hp concentrations, such that LPS treatments increased between 24 and $48 \mathrm{~h}$ postbolus, whereas $\mathrm{PF}$ treatments remained at baseline $(P<0.01 ;$ Figure $4 \mathrm{C})$. Interestingly, there was a decrease $(51 \%)$ at $48 \mathrm{~h}$ postbolus in LPS-Cr cows relative LPS-CON cows $(P=0.02)$. Blood ionized calcium of LPS-administered cows was decreased $39 \%$ at $12 \mathrm{~h}$ postbolus and temporally increased to within $12 \%$ of PF cows by $48 \mathrm{~h}$ postbolus $(P<0.01$; Figure $4 \mathrm{D})$.

Circulating white blood cells (WBC) were initially decreased between 3 and $12 \mathrm{~h}$ postbolus (about $60 \%$ ) in LPS cows relative to PF cows $(P<0.01$; Figure 

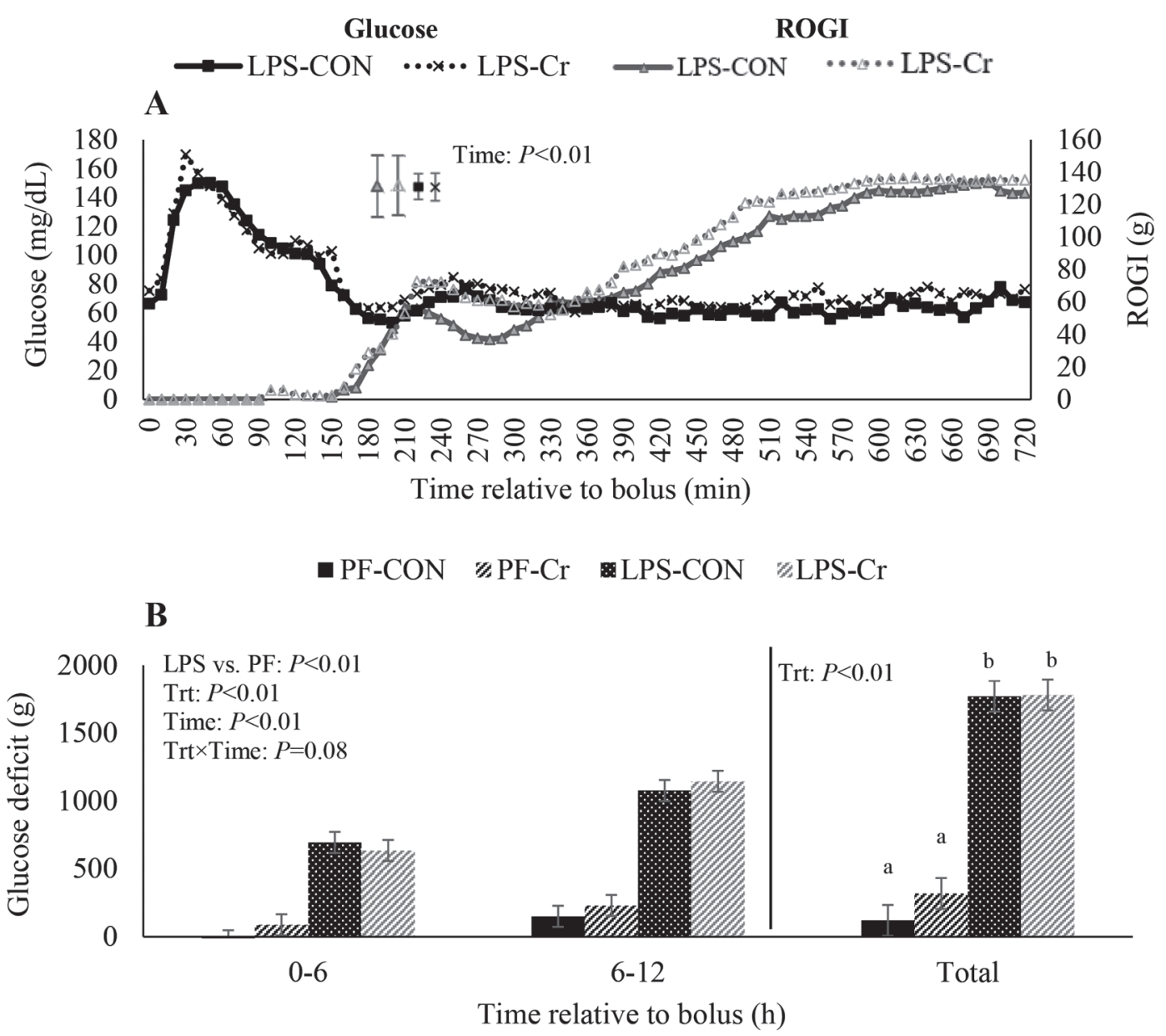

Figure 2. (A) Effects of an LPS bolus in cows fed a control diet (CON) or a chromium (Cr) propionate-supplemented diet on circulating glucose and rate of glucose infusion (ROGI). (B) Effects of an LPS bolus or pair feeding in cows fed a control diet (CON) or a chromium (Cr) propionate-supplemented diet on milk or total glucose deficit from 0 to $6 \mathrm{~h}$, from 6 to $12 \mathrm{~h}$, and accumulated over $12 \mathrm{~h}$. Values with differing letters $(\mathrm{a}, \mathrm{b})$ denote differences $(P<0.05)$ between treatments $(\mathrm{Trt}) . \mathrm{PF}-\mathrm{CON}=$ pair-fed, saline bolus, control; $\mathrm{PF}-\mathrm{Cr}=$ pair-fed, saline bolus, chromium; LPS-CON = ad libitum, LPS bolus, control; LPS-Cr $=$ ad libitum, LPS bolus, chromium. Vertical bars represent SEM.

5A), after which LPS cows developed leukocytosis (59\% increase relative to PF; $P<0.01$ ). Circulating neutrophils reflected a similar pattern to that of circulating WBC $(P<0.01$; Figure 5B). Although Cr supplementation had no effect on overall neutrophil number during P2, post-hoc analysis revealed that LPS-Cr cows had a $16 \%$ increase in their peak neutrophil number at $30 \mathrm{~h}$ postbolus $(P=0.05)$ and a $14 \%$ increase at $36 \mathrm{~h}$ postbolus relative to LPS-CON cows $(P=0.09$; Figure 5B). Further, between 18 and $48 \mathrm{~h}$ postbolus, LPS-Cr cows had increased neutrophil number $(12 \% ; P=0.04)$ relative to LPS-CON cows.

Patterns of circulating lymphocytes and monocytes also mirrored total WBC patterns, with an initial marked decrease followed by a steady increase $(P=$ 0.01; Figure 5C; Table 3). Circulating lymphocytes and monocytes of LPS treatments exceeded PF treatments at $48 \mathrm{~h}$ postbolus and were increased 3 and $28 \%$, re- spectively $(P<0.01)$. Overall, Cr-supplemented cows had a $22 \%$ increase in monocyte cell number relative to control cows $(P=0.03$; Table 3$)$. Chromium supplementation decreased $(24 \%)$ eosinophil number in $\mathrm{PF}-\mathrm{Cr}$ cows relative to $\mathrm{PF}-\mathrm{CON}$ cows $(P=0.01$; Table 3). Platelets were decreased in LPS-administered cows relative to $\mathrm{PF}$ cows $(52 \% ; P<0.01$; Figure 3 ). Platelet counts from LPS-Cr cows were decreased $54 \%$ compared with LPS-CON cows $(P<0.01)$.

\section{DISCUSSION}

Immunostimulation homeorhetically alters systemic metabolism in a coordinated effort to meet the energetic demands of leukocytes. In response to immunogenic stimuli, immune cells become obligate glucose utilizers, and they switch their energetic metabolism from oxidative phosphorylation to aerobic glycolysis. 
This is known as the Warburg effect and allows for more rapid ATP production (Palsson-McDermott and O'Neill, 2013). Additionally, glucose-derived carbon is directed through the pentose phosphate pathway to produce important intermediates to support proliferation and production of reactive oxygen species (Calder et al., 2007; Palsson-McDermott and O'Neill, 2013).

Delivering energetic substrates to activated leukocytes is a critical component in successfully mounting an effective immune response (MacIver et al., 2008). Bovine monocytes, neutrophils, and lymphocytes have GLUT3 and GLUT4 transporters (Maratou et al., 2007; O'Boyle et al., 2012), and O'Boyle et al. (2012) dem- onstrated increased mRNA expression of GLUT3 and GLUT4 upon endotoxin stimulation. Improved glucose availability to activated leukocytes increases their longevity and function (e.g., phagocytosis, reactive oxygen species production; Sagone et al., 1974; Furukawa et al., 2000; Healy et al., 2002; Garcia et al., 2015). Lee et al. (2000) reported increased glucose uptake and macrophage function with $\mathrm{Cr}$ supplementation in vitro, likely due to Cr's role in improving insulin sensitivity. Ensuring an adequate glucose supply for immune cells is not limited to leukocyte glucose uptake mechanisms but rather also relies on altered systemic glucose partitioning and availability. During immunoactivation,
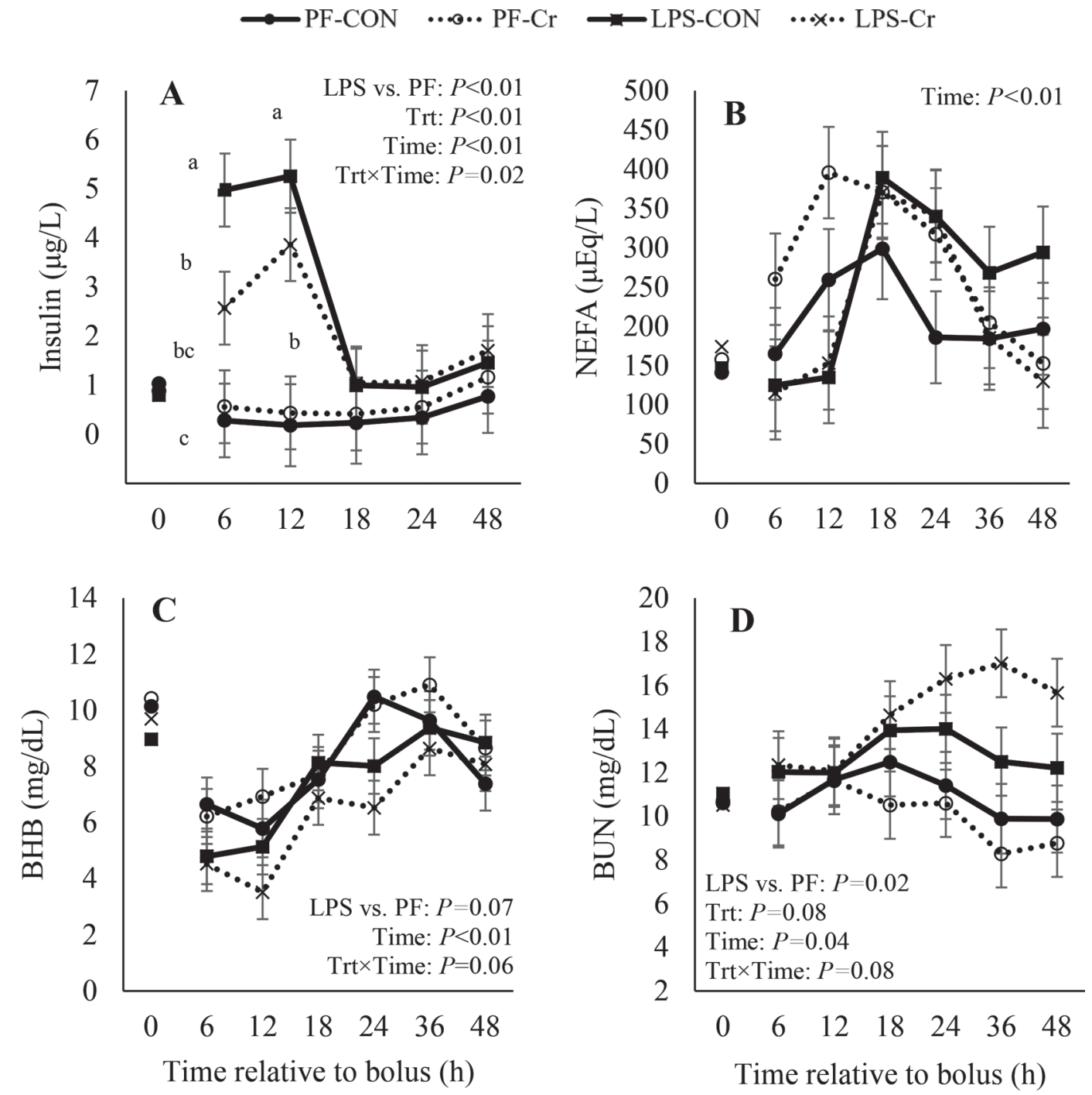

Figure 3. Effects of an LPS bolus or pair feeding in cows fed a control diet (CON) or a chromium (Cr) propionate-supplemented diet on circulating (A) insulin, (B) nonesterified fatty acids (NEFA), (C) BHB, and (D) BUN. PF-CON = pair-fed, saline bolus, control; PF-Cr = pairfed, saline bolus, chromium; LPS-CON $=$ ad libitum, LPS bolus, control; LPS-Cr $=$ ad libitum, LPS bolus, chromium. Values with differing letters $(\mathrm{a}-\mathrm{c})$ denote differences $(P<0.05)$ between treatments $($ Trt $)$. Vertical bars represent SEM. 
skeletal muscle and adipose tissue become insulin resistant and the mammary gland reduces glucose uptake; these energetic shifts reflect synchronized efforts to spare glucose for the new dominant physiological state (Maitra et al., 2000). Therefore, we hypothesized that $\mathrm{Cr}$ would increase leukocyte glucose consumption and thus increase the total glucose deficit during an LPSeuglycemic clamp.

Herein, we demonstrated successful immunoactivation as reflected by increased circulating acute phase proteins (APP; including SAA, Hp, and LBP), mild febrile response, initial leukopenia and subsequent leu- kocytosis, hypogalactia, and hypophagia. The transient febrile response observed is similar to that in previous studies (Giri et al., 1990; Waldron et al., 2003b; Vernay et al., 2012; Moyes et al., 2014) and agrees with Lang et al. (1987) that increased glucose utilization continues independently of increased $\operatorname{Tr}$ during immunoactivation.

Leukopenia occurred immediately following LPS administration, and this agrees with previous ruminant reports (Griel et al., 1975; Gerros et al., 1995; Bieniek et al., 1998). Leukopenia likely represents immune cell infiltration into tissues or may be explained by shifts

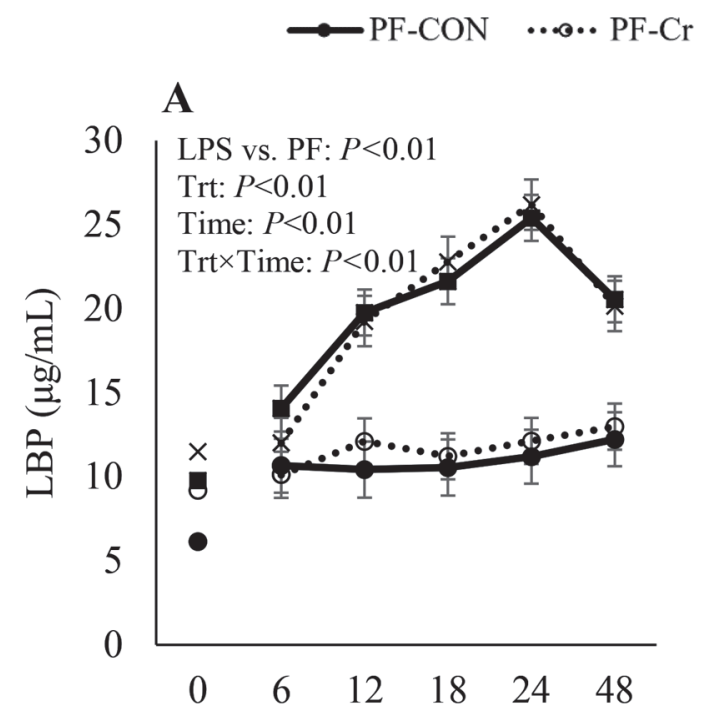

$\leadsto$ LPS-CON $\quad \cdots \times \cdot \cdot$ LPS-Cr
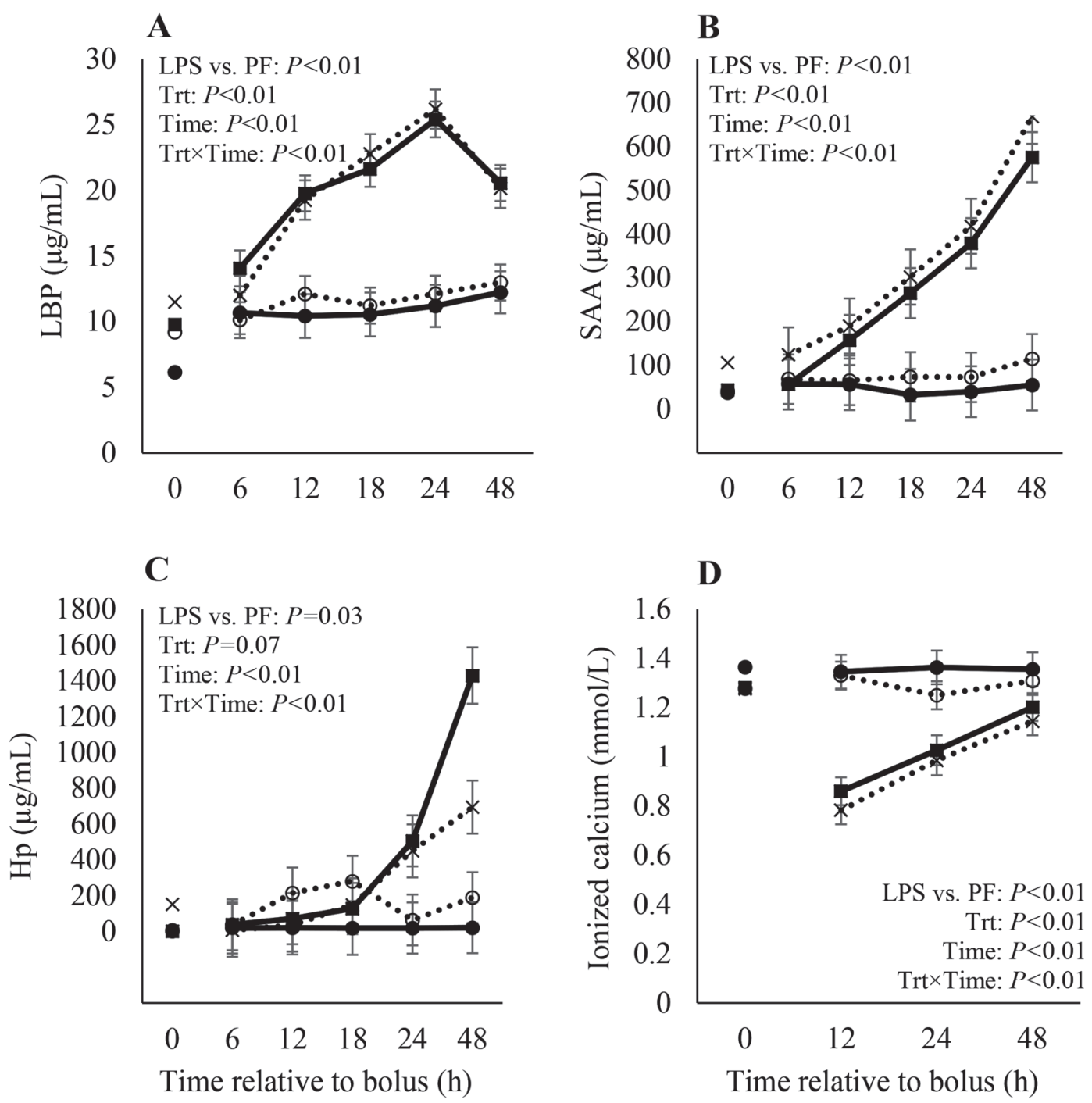

Figure 4. Effects of an LPS bolus or pair feeding in cows fed a control diet (CON) or a chromium $(\mathrm{Cr})$ propionate-supplemented diet on circulating (A) LPS binding protein (LBP), (B) serum amyloid A (SAA), (C) haptoglobin (Hp), and (D) ionized calcium. PF-CON = pair-fed, saline bolus, control; PF-Cr = pair-fed, saline bolus, chromium; LPS-CON = ad libitum, LPS bolus, control; LPS-Cr $=$ ad libitum, LPS bolus, chromium; Trt $=$ treatment. Vertical bars represent SEM. 
from circulating systemic leukocytes into the marginated pool (Hoedemaker et al., 1992; Lang et al., 1992). Within 12 to $18 \mathrm{~h}$ postbolus, lymphocyte and monocyte counts had returned to preinfusion levels; however, neutrophil counts exceeded baseline values by $12 \mathrm{~h}$ postbolus. Subsequent neutrophilia may indicate increased neutrophil production, demargination from pulmonary circulation, or decreased endothelial adherence (Jagels and Hugli, 1994; Opdenakker et al., 1998). Bannerman et al. (2008) observed a similar dynamic change in circulating WBC and neutrophils when evaluated over time. The fluctuating temporal pattern of leukocytes

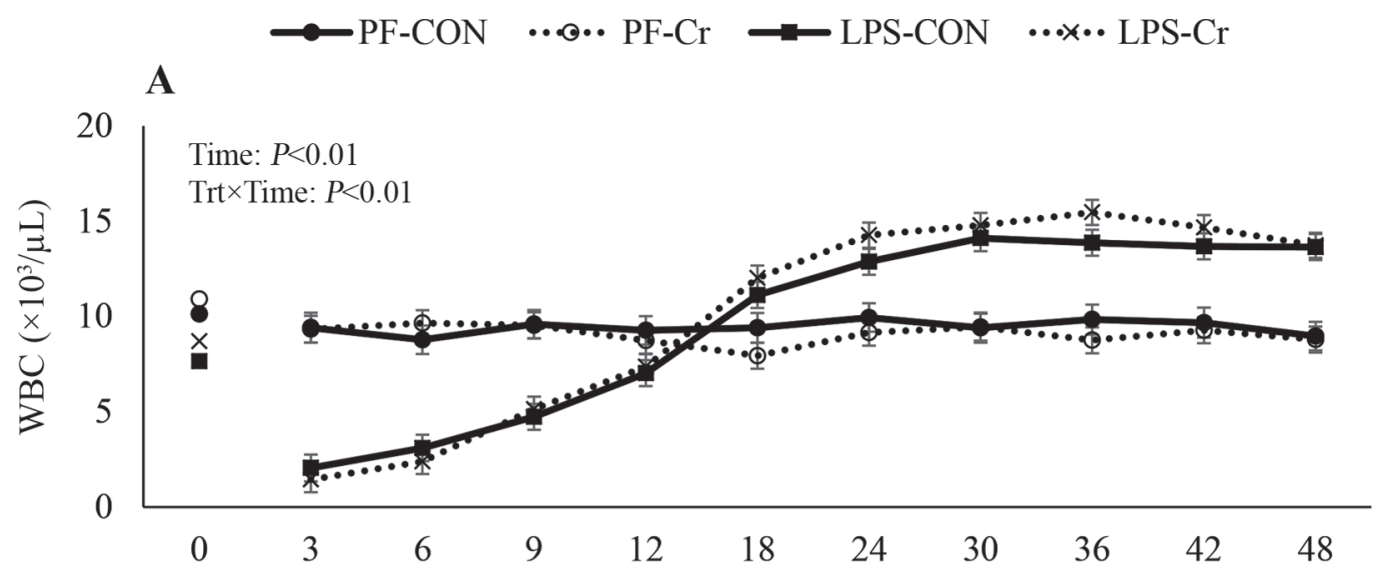

B
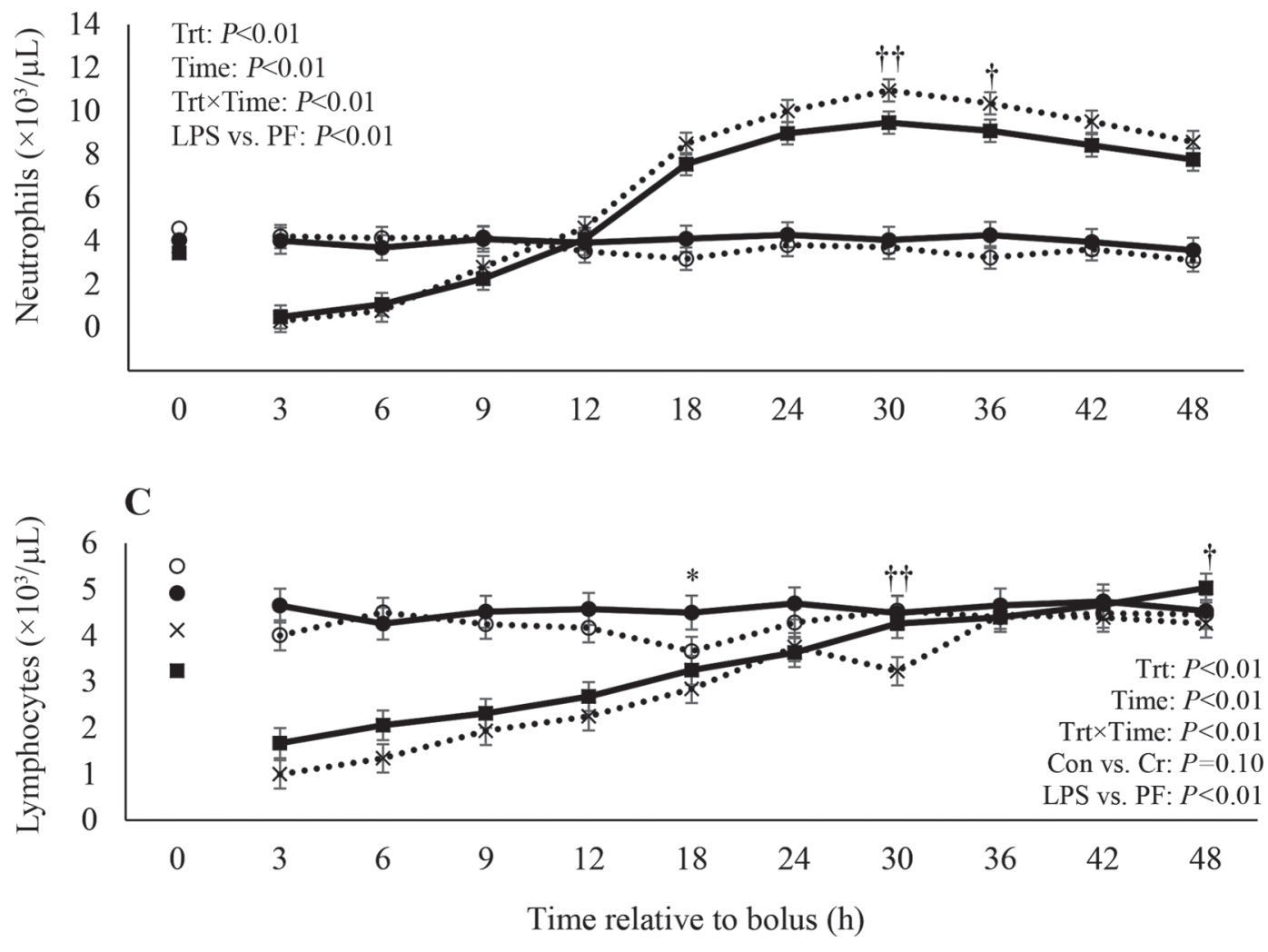

Figure 5. Effects of an LPS bolus or pair feeding in cows fed a control diet (CON) or a chromium (Cr) propionate-supplemented diet on circulating (A) white blood cell (WBC), (B) neutrophil, and (C) lymphocyte counts. †Tendency for a difference between LPS-CON and LPSCr treatments $(P<0.10)$; ††significant difference between LPS-CON and LPS-Cr treatments $(P<0.05)$; *tendency for a difference between PF-CON and PF-Cr treatments $(P<0.10)$; ${ }^{* *}$ significant difference between PF-CON and PF-Cr treatments $(P<0.05)$. PF-CON $=$ pair-fed, saline bolus, control; PF-Cr = pair-fed, saline bolus, chromium; LPS-CON = ad libitum, LPS bolus, control; LPS-Cr $=$ ad libitum, LPS bolus, chromium; Trt $=$ treatment. Vertical bars represent SEM. 
demonstrates the importance of frequent and repeated sampling in accurately assessing changes in number and function of WBC following immunoactivation.

The role of $\mathrm{Cr}$ in improving leukocyte insulin action has led several to investigate whether it can improve immunity. Although not always consistent (Chang et al., 1996; Kegley et al., 1997b), previous studies have reported improved immune function (e.g., phagocytosis, blastogenic response, antibody production) of activated leukocytes when animals were supplemented with $\mathrm{Cr}$ (Moonsie-Shageer and Mowat, 1993; Chang et al., 1996; Lee et al., 2000). Increased cytokine production with Cr supplementation has also been observed in mice, steers, and lactating cows (Burdick et al., 2012; Yuan et al., 2014; Jin et al., 2016). Herein we observed increased circulating neutrophil counts in LPS-administered cows supplemented with $\mathrm{Cr}$, and this agrees with others (Kafilzadeh et al., 2012; Yasui et al., 2014; Mayorga et al., 2016). Although mechanisms for increased circulating neutrophils with $\mathrm{Cr}$ supplementation are not fully understood, it may relate to increased insulin sensitivity within bone marrow, the site of immune cell proliferation (Faulhaber et al., 2009). Increased neutrophils in the blood of Cr-supplemented cows may also be explained by reduced rates of apoptosis mediated by Cr-induced increased glucose uptake (Healy et al., 2002). Immunomodulatory effects of $\mathrm{Cr}$ have also been attributed to its counteractive effects on immunosuppressors such as glucocorticoids, namely by decreasing circulating cortisol (Kafilzadeh et al., 2012). Regardless of the mechanism, it is of interest to determine whether Cr-induced increases in neutrophils translate into improved whole-animal well-being and productivity.

In addition to markedly altering immune cell dynamics, LPS initiates a well-characterized biphasic response in circulating glucose, with an initial period of hyperglycemia followed by severe hypoglycemia (Lohuis et al., 1988; Waldron et al., 2003a; Zarrin et al., 2014). In agreement with Kvidera et al. (2017b), LPS administration induced marked hyperglycemia for the first approximately $180 \mathrm{~min}$ postbolus, after which continuous glucose infusion was necessary to maintain euglycemia. Bernhard et al. (2012) reported increased peak circulating glucose in Cr-supplemented steers relative to controls immediately following LPS exposure. The increased hyperglycemic response may reflect an increased capacity to store liver glycogen, and thus Cr-fed animals would have more extensive capacity for glycogenolysis and hepatic glucose output. Improved liver glycogen storage with $\mathrm{Cr}$ supplementation has been observed previously (Rosebrough and Steele, 1981; Brooks et al., 2016). However, no differences in peak glucose response following LPS administration were observed in the present study, and this agrees with 
others (Lee et al., 2000; Lein et al., 2005). Reasons for inconsistencies in the LPS-induced hyperglycemic response with $\mathrm{Cr}$ supplementation are not clear but may be explained by small sample size, differences in species or physiological states, Cr dose, or LPS dose and administration routes.

We predicted that the LPS dose selected for the current study would decrease milk yield by 40 to $50 \%$; however, despite the LPS dose being only $25 \%$ of that of our previous report (Kvidera et al., 2017b), the milk production response and the total glucose deficit accumulated over $12 \mathrm{~h}$ were similar among studies. This likely indicates that the dose in both experiments $(0.375$ and $1.5 \mu \mathrm{g} / \mathrm{kg}$ of BW) was large enough to induce the maximal response in leukocyte glucose consumption. When evaluated on a metabolic BW basis, the glucose requirement of the immune system in the current study is approximately $1.0 \mathrm{~g} / \mathrm{kg}$ of $\mathrm{BW}^{0.75}$ per hour, comparable with $0.66,1.0$, and $1.1 \mathrm{~g} / \mathrm{kg}$ of $\mathrm{BW}^{0.75}$ per hour reported in cows, steers, and pigs, respectively (Kvidera et al., 2016, 2017b,c). In contrast to our hypothesis, no differences in the total glucose deficit were detected between LPS-CON and LPS-Cr cows. However, the current model does not account for liver's contribution (via gluconeogenesis or glycogenolysis) to the circulating glucose pool, a clear limitation to the experimental model. In particular, not accounting for glycogenolysis during the hyperglycemic phase causes the total glucose deficit to be underestimated (i.e., we are unable to estimate immune system's glucose use during the first $\sim 180$ min). Additionally, increased gluconeogenic rates occur following LPS exposure in small animal models (Spitzer et al., 1985; McGuinness, 1994) and ruminants (Waldron et al., 2003b), thus hepatic glucose output during immunoactivation increases because of both glycogenolysis and gluconeogenesis. Further, previous studies have reported increased circulating glucagon in Cr supplemented cows (Smith et al., 2008; Sadri et al., 2012) and, although speculation, increased gluconeogenesis in response to increased glucagon may allow for increased glucose availability to immune cells, which could not be detected with the current model. Interestingly, we observed an improved immune response, as indicated by increased neutrophil number, in LPS-Cr cows despite no differences in glucose deficit. Therefore, further investigating the contribution of glycogenolysis and gluconeogenesis to leukocyte glucose utilization and the potential beneficial effect $\mathrm{Cr}$ has on this response is of both academic and practical interest.

Determining differences in production outcomes was not the primary objective, as the experiment was knowingly underpowered to detect treatment differences in such variable measurements. Nonetheless, analyzing and presenting production variables allows for the pri- mary aims (glucose dynamics and immune responses) to be put into context. Despite maintaining euglycemia, milk yield was not rescued with i.v. glucose infusion ( $74 \%$ decrease at $12 \mathrm{~h}$ postbolus), and this agrees with our previous study (Kvidera et al., 2017b) and confirms hypoglycemia is not responsible for reduced milk synthesis during an infection. Decreased milk yield is typical during infection and it represents an important glucose-sparing strategy during immunoactivation. The effects of LPS on milk synthesis may be either direct via binding to mammary epithelial Toll-like receptor 4 or indirect by increased proinflammatory cytokines (Verheijden et al., 1983; Ibeagha-Awemu et al., 2008). Interestingly, milk yield from $\mathrm{Cr}$ supplemented cows was decreased $16 \%$, relative to controls throughout the LPS challenge, potentially resulting from Cr-induced increased leukocyte glucose consumption. This tenet is partially supported by the milk glucose deficit $(P$ $=0.15)$ of $\mathrm{Cr}$ supplemented cows being numerically increased, relative to controls. However, the biological importance of this trend and how it relates to our hypothesis requires further investigation.

To eliminate the confounding effects of dissimilar nutrient intake, a pair-feeding model was utilized throughout the LPS challenge. Total glucose deficit of PF treatments was accounted for exclusively by the decrease in milk yield, whereas the deficit of LPS treatments included the decrease in milk yield in addition to infused glucose. Although cows remained on the same plane of nutrition, the milk glucose deficit of LPS treatments was 4-fold greater than the PF controls. Despite a variety of studies demonstrating beneficial effects of Cr supplementation on DMI and milk yield (Hayirli et al., 2001; McNamara and Valdez, 2005; Smith et al., 2005) we observed little or no differences in traditional productive traits between control and $\mathrm{Cr}$ treatments during P2. At the initiation of P3 all treatments were allowed to consume feed ad libitum; however, DMI and milk yield from previously LPS infused cows remained below that of PF treatments. Further, DMI of Cr supplemented treatments tended to be decreased relative to controls. The delayed return to baseline feed intake and milk yield agrees with others (Waldron et al., 2003b; Bannerman et al., 2008; Aditya et al., 2017) and demonstrates the long-term consequences of inflammation. It is possible the improved DMI previously reported by others supplementing $\mathrm{Cr}$ was not observed in the current study due to small sample size and severity of the immune insult.

Despite being in a catabolic state, ruminant and monogastric animals become hyperinsulinemic following LPS exposure (Waldron et al., 2003b; Zarrin et al., 2014; Kvidera et al., 2017b). The mechanism of LPSinduced hyperinsulinemia has not been fully elucidated 
but it could be indirect via glucagon-like peptide 1 (Nguyen et al., 2014) or the direct result of LPS on glucose stimulated insulin secretion as we have recently reviewed (Baumgard et al., 2016); regardless, insulin serves as an important mediator of glucose uptake by activated immune cells (Calder et al., 2007) and LPS-triggered hyperinsulinemia may be a conserved evolutionary strategy. Continuous glucose infusion may partially explain the hyperinsulinemic state, as an interaction between LPS and glucose infusion has been suggested (Blackard et al., 1976). However, our previous study observed no differences in insulin between cows maintained at euglycemia and cows allowed to develop hypoglycemia, confirming glucose infusion is not the prime mediator of hyperinsulinemia and the continued increase in circulating insulin occurs for hours despite eventual LPS-induced hypoglycemia (Kvidera et al., 2017b). Consequently, acute hyperglycemia is not responsible for the chronic hyperinsulinemia. Further, fasted pigs administered LPS become hyperinsulinemic, despite having a blunted hyperglycemic response (Kvidera et al., 2017c). Interestingly, we observed an attenuated insulin response during the hyperglycemic phase in cows supplemented with Cr. There is conflicting evidence on Cr's role in the insulin response to a glucose tolerance test, as both increased (Striffler et al., 1995; Kegley et al., 2000) and decreased (Subiyatno et al., 1996; Kegley et al., 1997a; Hayirli et al., 2001; Stahlhut et al., 2006; Leiva et al., 2015) concentrations have been observed. With no differences observed in total glucose deficit, the decreased insulin response in Cr-supplemented cows suggests increased insulin sensitivity, presumably, of activated leukocytes.

As would be expected given insulin's antilipolytic characteristics, circulating NEFA response was blunted during the first $12 \mathrm{~h}$ of the LPS challenge, after which NEFA began to increase. This disagrees with many studies that observe a steady increase in NEFA postLPS bolus (Waldron et al., 2003b; Graugnard et al., 2013; Moyes et al., 2014). Insulin-mediated lipolysis inhibition may also be influenced by hyperlactatemia as previously described by Ahmed et al. (2010). Despite previous transition cow literature (Hayirli et al., 2001; Kafilzadeh et al., 2012), no effects of Cr were observed on NEFA mobilization in the current study. The temporal pattern of ketones was very different than NEFA, as circulating BHB initially decreased in response to LPS before gradually returning to baseline values; this agrees with other ruminant models (Waldron et al., 2003b; Graugnard et al., 2013; Zarrin et al., 2014). The mechanism behind decreased BHB is not fully understood, but it may be due to increased ketone utilization by peripheral tissue in an effort to spare glucose for the immune system (Zarrin et al., 2014). Understanding the LPS-mediated changes in NEFA and BHB metabolism would presumably provide key insight into how fuel preferences and nutrient partitioning are reprioritized during immunoactivation.

Sepsis-induced muscle proteolysis is another strategy used to support the demand for gluconeogenic precursors and AA for APP synthesis. Due to differences in AA composition between APP and skeletal muscle, a considerable amount of muscle proteolysis must occur to support APP synthesis (Reeds et al., 1994). In ruminant models, BUN can be hard to interpret as muscle proteolysis is not the sole source of urea. Similar to the other metabolites, little change in BUN was observed during the first $12 \mathrm{~h}$ postbolus; however, beginning after $12 \mathrm{~h}$, there was a progressive increase over time. This may be due to cessation of the clamp and thus greater need for gluconeogenic precursors to supply glucose. Interestingly, BUN from LPS-Cr cows was increased relative to all other treatments. In a noninflammatory state, $\mathrm{Cr}$ supplementation would normally increase muscle insulin sensitivity; this scenario would presumably blunt proteolysis, but this is clearly not the case in an immunoactivated state. Evaluating direct markers of protein degradation, such as 3-methyl histidine, may allow for a more accurate assessment of Cr's role in LPS-induced proteolysis.

Severe hypocalcemia is a well-described response to endotoxin exposure (Waldron et al., 2003a; Holowaychuk et al., 2009), and it was sustained throughout the sampling period in the current study. Calcium prevents LPS disaggregation and interferes with LPS binding to lipoproteins (Munford et al., 1981). Thus, LPS-induced hypocalcemia may be a survival mechanism to promote LPS detoxification via lipoproteins to prevent an overinflammatory response (Skarnes, 1968). Gaining a better understanding of the direct and indirect role $\mathrm{Ca}$ plays in immune function has practical implications to the dairy industry.

In agreement with our previous clamp studies, it is clear that immunoactivation causes drastic changes in glucose metabolism. Taken together, our results suggest that $\mathrm{Cr}$ has little effect on total glucose deficit in response to severe LPS challenge. However, future work should focus on evaluating whether $\mathrm{Cr}$ increases hepatic gluconeogenesis rates during immunoactivation, as this may explain why no overall differences were observed in glucose deficit in the current study. Further, focusing on the molecular changes in insulin signaling and GLUT expression of immune cells isolated from Cr-supplemented cows administered LPS may allow for a better understanding of the mechanism by which $\mathrm{Cr}$ is functioning. Interestingly, in the current study the 
increased neutrophil number occurred despite no differences in total glucose deficit, suggesting more efficient neutrophil glucose utilization with $\mathrm{Cr}$ supplementation.

\section{CONCLUSIONS}

Our results corroborate data collected from our previous clamp studies indicating that a substantial amount of glucose is utilized in response to an immunogenic stimulus. Further, we have demonstrated potential immunomodulatory effects (e.g., increased circulating neutrophils) of $\mathrm{Cr}$ supplementation following immunoactivation. The increase in circulating immune cells was observed despite no detected effect of $\mathrm{Cr}$ on total glucose deficit following LPS administration. In addition, Cr supplementation decreased circulating insulin in response to LPS, highlighting its potential role in improving immune cell insulin sensitivity. Future work should focus on the direct effects of $\mathrm{Cr}$ on immune cell signaling and glucose utilization and hepatic glucose metabolism in response to inflammation.

\section{ACKNOWLEDGMENTS}

This project was supported in part by Kemin Industries (Des Moines, IA).

\section{REFERENCES}

Aditya, S., E. Humer, P. Pourazad, R. Khiaosa-Ard, J. Huber, and Q. Zebeli. 2017. Intramammary infusion of Escherichia coli lipopolysaccharide negatively affects feed intake, chewing, and clinical variables, but some effects are stronger in cows experiencing subacute rumen acidosis. J. Dairy Sci. 100:1363-1377.

Ahmed, K., S. Tunaru, C. Tang, M. Muller, A. Gille, A. Sassmann, J. Hanson, and S. Offermanns. 2010. An autocrine lactate loop mediates insulin-dependent inhibition of lipolysis through GPR81. Cell Metab. 11:311-319.

AOAC International. 1995. AOAC official method 972.16. Fat, lactose, protein, and solids in milk. Mid infrared spectroscopic method. Pages 23-26 in Official Methods of Analysis. 16th ed. Vol. 2. AOAC International, Arlington, VA.

Ballou, M. A. 2012. Growth and development symposium: Inflammation: Role in the etiology and pathophysiology of clinical mastitis in dairy cows. J. Anim. Sci. 90:1466-1478.

Bannerman, D. D., A. C. W. Kauf, M. J. Paape, H. R. Springer, and J. P. Goff. 2008. Comparison of Holstein and Jersey innate immune responses to Escherichia coli intramammary infection. J. Dairy Sci. 91:2225-2235.

Bauman, D. E., and W. B. Currie. 1980. Partitioning of nutrients during pregnancy and lactation: A review of mechanisms involving homeostasis and homeorhesis. J. Dairy Sci. 63:1514-1529.

Baumgard, L. H., R. J. Collier, and D. E. Bauman. 2017. A 100 year review: Regulation of nutrient partitioning to support lactation. J. Dairy Sci. 100:10353-10366.

Baumgard, L. H., G. J. Hausman, and M. V. Sanz Fernandez. 2016. Insulin: Pancreatic secretion and adipocyte regulation. Domest. Anim. Endocrinol. 54:76-84.

Baumgard, L. H., J. B. Wheelock, S. R. Sanders, C. E. Moore, H. B. Green, M. R. Waldron, and R. P. Rhoads. 2011. Postabsorptive carbohydrate adaptations to heat stress and monensin supplementation in lactating Holstein cows. J. Dairy Sci. 94:5620-5633.

Bernhard, B. C., N. C. Burdick, W. Rounds, R. J. Rathmann, J. A. Carroll, D. N. Finck, M. A. Jennings, T. R. Young, and B. J. Johnson. 2012. Chromium supplementation alters the performance and health of feedlot cattle during the receiving period and enhances their metabolic response to a lipopolysaccharide challenge. J. Anim. Sci. 90:3879-3888.

Bieniek, K., A. Szuster-Ciesielska, T. Kamińska, M. Kondracki, M. Witek, and M. Kandefer-Szerszeń. 1998. Tumor necrosis factor and interferon activity in the circulation of calves after repeated injection of low doses of lipopolysaccharide. Vet. Immunol. Immunopathol. 62:297-307.

Blackard, W. G., J. H. Anderson, and J. J. Spitzer. 1976. Hyperinsulinism in endotoxin shock dogs. Metabolism 25:675-684.

Bradford, B. J., K. Yuan, J. K. Farney, L. K. Mamedova, and A. J. Carpenter. 2015. Invited review: Inflammation during the transition to lactation: New adventures with an old flame. J. Dairy Sci. 98:6631-6650.

Brooks, M. A., J. L. Grimes, K. E. Lloyd, K. Krafka, A. Lamptey, and J. W. Spears. 2016. Chromium propionate in broilers: Effect on insulin sensitivity. Poult. Sci. 95:1096-1104.

Burdick, N. C., B. C. Bernhard, J. A. Carroll, R. J. Ratmann, and B. J. Johnson. 2012. Enhancement of the acute phase response to a lipopolysaccharide challenge in steers supplemented with chromium. Innate Immun. 18:592-601.

Calder, P. C., G. Dimitriadis, and P. Newsholme. 2007. Glucose metabolism in lymphoid and inflammatory cells and tissues. Curr. Opin. Clin. Nutr. Metab. Care 10:531-540.

Chang, X., B. A. Mallard, and D. N. Mowat. 1996. Effects of chromium on health status, blood neutrophil phagocytosis and in vitro lymphocyte blastogenesis of dairy cows. Vet. Immunol. Immunopathol. 52:37-52.

Chen, G., P. Liu, G. R. Pattar, L. Tackett, P. Bhonagiri, A. B. Strawbridge, and J. S. Elmendorf. 2006. Chromium activates glucose transporter 4 trafficking and enhances insulin-stimulated glucose transport in 3T3-L1 adipocytes via a cholesterol-dependent mechanism. Mol. Endocrinol. 20:857-870.

De Koster, J. D., and G. Opsomer. 2013. Insulin resistance in dairy cows. Vet. Clin. North Am. Food Anim. Pract. 29:299-322.

Faulhaber, G. A. M., M. O. Premaor, H. L. Moser Filho, L. M. Silla, and T. W. Furlanetto. 2009. Low bone mineral density is associated with insulin resistance in bone marrow transplant subjects. Bone Marrow Transplant 43:953-957.

Furukawa, S., H. Saito, T. Matsuda, T. Inoue, K. Fukatsu, I. Han, S. Ikeda, A. Hidemura, and T. Muto. 2000. Relative effects of glucose and glutamine on reactive oxygen intermediate production by neutrophils. Shock 13:274-278.

Garcia, M., T. H. Elsasser, Y. Qu, X. Zhu, and K. M. Moyes. 2015. Glucose supplementation has minimal effects on blood neutrophil function and gene expression in vitro. J. Dairy Sci. 98:6139-6150.

Gerros, T. C., S. D. Semrad, and R. A. Proctor. 1995. Alterations in clinical, hematological and metabolic variables in bovine neonatal endotoxemia. Can. J. Vet. Res. 59:34-39.

Giri, S. N., P. Emau, J. S. Cullor, G. H. Stabenfeldt, M. L. Bruss, R. H. Bondurant, and B. I. Osburn. 1990. Effects of endotoxin infusion on circulating levels of eicosanoids, progesterone, cortisol, glucose and lactic acid, and abortion in pregnant cows. Vet. Microbiol. 21:211-231.

Graugnard, D. E., K. M. Moyes, E. Trevisi, M. J. Khan, D. Keisler, J. K. Drackley, G. Bertoni, and J. J. Loor. 2013. Liver lipid content and inflammometabolic indices in peripartal dairy cows are altered in response to prepartal energy intake and postpartal intramammary inflammatory challenge. J. Dairy Sci. 96:918-935.

Griel, L. C., A. Zarkower, and R. J. Eberhart. 1975. Clinical and clinico-pathological effects of Escherichia coli endotoxin in mature cattle. Can. J. Comp. Med. 39:1-6.

Hayirli, A., D. R. Bremmer, S. J. Bertics, M. T. Socha, and R. R. Grummer. 2001. Effect of chromium supplementation on production and metabolic parameters in periparturient dairy cows. J Dairy Sci. 84:1218-1230. 
Healy, D. A., R. W. Watson, and P. Newsholme. 2002. Glucose, but not glutamine, protects against spontaneous and anti-Fas antibodyinduced apoptosis in human neutrophils. Clin. Sci. 103:179-189.

Hoedemaker, M., L. A. Lund, and W. C. Wagner. 1992. Function of neutrophils and chemoattractant properties of fetal placental tissue during the last month of pregnancy in cows. Am. J. Vet. Res. 53:1524-1529.

Holowaychuk, M. K., B. D. Hansen, T. C. DeFrancesco, and S. L. Marks. 2009. Ionized hypocalcemia in critically ill dogs. J. Vet. Intern. Med. 23:509-513.

Ibeagha-Awemu, E. M., J. W. Lee, A. E. Ibeagha, D. D. Bannerman, M. J. Paape, and X. Zhao. 2008. Bacterial lipopolysaccharide induced increased expression of toll-like receptor (TLR) 4 and downstream TLR signaling molecules in bovine mammary epithelial cells. Vet. Res. 39:11.

Jagels, M. A., and T. E. Hugli. 1994. Mechanisms and mediators of neutrophilic leukocytosis. Immunopharmacology 28:1-18.

Jin, Y., L. Liu, S. Zhang, B. Tao, R. Tao, X. He, L. Qu, J. Huang, X. Wang, and Z. Fu. 2016. Chromium alters lipopolysaccharideinduced inflammatory responses both in vivo and in vitro. Chemosphere 148:436-443.

Kafilzadeh, F., H. Karami Shabankareh, and M. R. Targhibi. 2012. Effect of chromium supplementation on productive and reproductive performances and some metabolic parameters in late gestation and early lactation of dairy cows. Biol. Trace Elem. Res. 149:42-49.

Kegley, E. B., D. L. Galloway, and T. M. Fakler. 2000. Effect of dietary chromium-L-methionine on glucose metabolism of beef steers. J. Anim. Sci. 78:3177-3183.

Kegley, E. B., J. W. Spears, and T. T. Brown. 1997b. Effect of shipping and chromium supplementation on performance, immune response, and disease resistance of steers. J. Anim. Sci. 75:1956-1964.

Kegley, E. B., J. W. Spears, and J. H. Eisemann. 1997a. Performance and glucose metabolism in calves fed a chromium-nicotinic acid complex or chromium chloride. J. Dairy Sci. 80:1744-1750.

Kronfeld, D. S. 1982. Major metabolic determinants of milk volume, mammary efficiency, and spontaneous ketosis in dairy cows. J. Dairy Sci. 65:2204-2212.

Kvidera, S. K., M. J. Dickson, M. Abuajamieh, D. B. Snider, M. V. Sanz Fernandez, J. S. Johnson, A. F. Keating, P. J. Gorden, H. B. Green, K. M. Schoenberg, and L. H. Baumgard. 2017a. Intentionally induced intestinal barrier dysfunction causes inflammation, affects metabolism, and reduces productivity in lactating Holstein cows. J. Dairy Sci. 100:4113-4127.

Kvidera, S. K., E. A. Horst, M. Abuajamieh, E. J. Mayorga, M. V. Sanz Fernandez, and L. H. Baumgard. 2016. Technical note: A procedure to estimate glucose requirements of an activated immune system in steers. J. Anim. Sci. 94:4591-4599.

Kvidera, S. K., E. A. Horst, M. Abuajamieh, E. J. Mayorga, M. V. Sanz Fernandez, and L. H. Baumgard. 2017b. Glucose requirements of an activated immune system in lactating Holstein cows. J. Dairy Sci. 100:2360-2374.

Kvidera, S. K., E. A. Horst, E. J. Mayorga, M. V. Sanz-Fernandez, M. Abuajamieh, and L. H. Baumgard. 2017c. Estimating glucose requirements of an activated immune system in growing pigs. J. Anim. Sci. 95:5020-5029.

Kvidera, S. K., E. A. Horst, M. V. Sanz Fernandez, M. Abuajamieh, S. Ganesan, P. J. Gorden, H. B. Green, K. M. Schoenberg, W. E. Trout, A. F. Keating, and L. H. Baumgard. 2017d. Characterizing effects of feed restriction on glucagon-like peptide 2 administration on biomarkers of inflammation and intestinal morphology. J. Dairy Sci. 100:9402-9417.

Lambert, G. P., C. V. Gisolfi, D. J. Berg, P. L. Moseley, L. W. Oberley, and K. C. Kregel. 2002. Selected contribution: Hyperthermia-induced intestinal permeability and the role of oxidative and nitrosative stress. J. Appl. Physiol. 92:1750-1761.

Lang, C. H., G. J. Bagby, H. L. Blakesley, and J. J. Spitzer. 1987. Fever is not responsible for the elevated glucose kinetics in sepsis Proc. Soc. Exp. Biol. Med. 185:455-461.

Lang, C. H., G. J. Bagby, C. Dobrescu, A. Ottlakan, and J. J. Spitzer. 1992. Sepsis- and endotoxin-induced increase in organ glucose uptake in leukocyte-depleted rats. Am. J. Physiol. 263:R1324-R1332.
Lang, C. H., C. Dobrescu, and K. Mészáros. 1990. Insulin-mediated glucose uptake by individual tissues during sepsis. Metabolism 39:1096-1107.

Lee, D. N., C. F. Weng, H. T. Yen, T. F. Shen, and B. J. Chen. 2000. Effects of chromium supplementation and lipopolysaccharide injection on physiological responses of weanling pigs. Asian-australas. J. Anim. Sci. 13:528-534.

Lein, T. F., K. H. Yang, and K. J. Lin. 2005. Effects of chromium propionate supplementation on growth performance, serum traits, and immune response in weaned pigs. Asian-australas. J. Anim. Sci. 18:403-408.

Leiva, T., R. F. Cooke, A. P. Brandão, A. C. Aboin, J. Rances, and J. L. M. Vasoconcelos. 2015. Effects of excessive energy intake and supplementation with chromium propionate on insulin resistance parameters, milk production, and reproductive outcomes of lactating dairy cows. Livest. Sci. 180:121-128.

Lohuis, J. A., J. H. Verheijden, C. Burvenich, and A. S. van Miert. 1988. Pathophysiological effects of endotoxins in ruminants. 2. Metabolic aspects. Vet. Q. 10:117-125.

MacIver, N. J., S. R. Jacobs, H. L. Wieman, J. A. Wofford, J. L. Coloff, and J. C. Rathmell. 2008. Glucose metabolism in lymphocytes is a regulated process with significant effects on immune cell function and survival. J. Leukoc. Biol. 84:949-957.

Maitra, S. R., M. M. Wojnar, and C. H. Lang. 2000. Alterations in tissue glucose uptake during the hyperglycemic and hypoglycemic phases of sepsis. Shock 13:379-385.

Maratou, E., G. Dimitriadis, A. Kollias, E. Boutati, V. Lambadiari, P. Mitrou, and S. A. Raptis. 2007. Glucose transporter expression on the plasma membrane of resting and activated white blood cells. Eur. J. Clin. Invest. 37:282-290.

Mayorga, E. J., S. K. Stoakes, J. Seibert, E. A. Horst, M. Abuajamieh, S. Lei, L. Ochoa, B. Kremer, and L. H. Baumgard. 2016. Effects of dietary chromium propionate during heat stress on finishing pigs. J. Anim. Sci. 94(E-Suppl. 1):334. (Abstr.)

McGuinness, O. P. 1994. The impact of infection on gluconeogenesis in the conscious dog. Shock 2:336-343.

McNamara, J. P., and F. Valdez. 2005. Adipose tissue metabolism and production responses to calcium propionate and chromium propionate. J. Dairy Sci. 88:2498-2507.

Moonsie-Shageer, S., and D. N. Mowat. 1993. Effect of level of supplemental chromium on performance, serum constituents, and immune status of stressed feeder calves. J. Anim. Sci. 71:232-238.

Moyes, K. M., T. Larsen, P. Sørensen, and K. L. Ingvartsen. 2014 Changes in various metabolic parameters in blood and milk during experimental Escherichia coli mastitis for primiparous Holstein dairy cows during early lactation. J. Anim. Sci. Biotechnol. 5:47.

Munford, R. S., C. L. Hall, and J. M. Dietcschy. 1981. Binding of Salmonella typhimurium lipopolysaccharides to rat high-density lipoproteins. Infect. Immun. 34:835-843.

Nguyen, A. T., S. Mandard, C. Dray, V. Deckert, P. Valet, P. Besnard, D. J. Drucker, L. Lagrost, and J. Grover. 2014. Lipopolysaccharide-mediated increase in glucose-stimulated insulin secretion: Involvement of the GLP-1 pathway. Diabetes 63:471-482.

NRC. 2001. Nutrient Requirements of Dairy Cattle. 7th rev. ed. Natl. Acad. Press, Washington, DC.

O'Boyle, N. J., G. A. Contreras, S. A. Mattmiller, and L. M. Sordillo. 2012. Changes in glucose transporter expression in monocytes of periparturient dairy cows. J. Dairy Sci. 95:5709-5719.

Opdenakker, G., W. E. Fibbe, and J. Van Damme. 1998. The molecular basis of leukocytosis. Immunol. Today 19:182-189.

Palsson-McDermott, E. M., and L. A. O'Neill. 2013. The Warburg effect then and now: From cancer to inflammatory diseases. BioEssays 35:965-973.

Reeds, P. J., C. R. Fjeld, and F. Jahoor. 1994. Do the differences between the amino acid compositions of acute-phase and muscle proteins have a bearing on nitrogen loss in traumatic states? J. Nutr. 124:906-910

Rosebrough, R. W., and N. Steele. 1981. Effect of supplemental dietary chromium or nicotinic acid on carbohydrate metabolism during basal, starvation, and refeeding periods in poults. Poult. Sci. 60:407-417. 
Sadri, H., H. R. Rahmani, M. Khorvash, G. R. Ghorbani, and R. M. Bruckmaier. 2012. Chromium supplementation and substitution of barley grain with corn: Effects on metabolite and hormonal responses in periparturient dairy cows. J. Anim. Physiol. Anim. Nutr. (Berl.) 96:220-227.

Sagone, A. L., A. F. LoBuglio, and S. P. Balcerzak. 1974. Alterations in hexose monophosphate shunt during lymphoblastic transformation. Cell. Immunol. 14:443-452.

Sheldon, I. M., E. J. Williams, A. N. Miller, D. M. Nash, and S. Herath. 2008. Uterine diseases in cattle after parturition. Vet. J. $176: 115-121$

Skarnes, R. C. 1968. In vivo interaction of endotoxin with a plasma lipoprotein having esterase activity. J. Bacteriol. 95:2031-2034.

Smith, K. L., M. R. Waldron, J. K. Drackley, M. T. Socha, and T. R. Overton. 2005. Performance of dairy cows as affected by prepartum dietary carbohydrate source and supplementation with chromium throughout the transition period. J. Dairy Sci. 88:255-263.

Smith, K. L., M. R. Waldron, L. C. Ruzzi, J. K. Drackley, M. T. Socha, and T. R. Overton. 2008. Metabolism of dairy cows as affected by prepartum dietary carbohydrate source and supplementation with chromium throughout the periparturient period. J. Dairy Sci. 91:2011-2020.

Spitzer, J. A., K. M. Nelson, and R. E. Fish. 1985. Time course of changes in gluconeogenesis from various precursors in chronically endotoxemic rats. Metabolism 34:842-849.

Stahlhut, H. S., C. S. Whisnant, K. E. Lloyd, E. J. Baird, L. R. Legleiter, S. L. Hansen, and J. W. Spears. 2006. Effect of chromium supplementation and copper status on glucose and lipid metabolism in Angus and Simmental beef cows. Anim. Feed Sci. Technol. 128:253-265.

Striffler, J. S., J. S. Law, M. M. Polansky, S. J. Bhathena, and R. A. Anderson. 1995. Chromium improves insulin response to glucose in rats. Metabolism 44:1314-1320.

Subiyatno, A., D. N. Mowat, and W. Z. Yang. 1996. Metabolite and hormonal responses to glucose or propionate infusions in periparturient dairy cows supplemented with chromium. J. Dairy Sci. 79:1436-1445.

Verheijden, J. H., A. S. Van Miert, A. J. Schotman, and C. T. Van Duin. 1983. Pathophysiological aspects of E. coli mastitis in ruminants. Vet. Res. Commun. 7:229-236.
Vernay, M. C., O. Wellnitz, L. Kreipe, H. A. van Dorland, and R. M. Bruckmaier. 2012. Local and systemic response to intramammary lipopolysaccharide challenge during long-term manipulated plasma glucose and insulin concentrations in dairy cows. J. Dairy Sci. 95:2540-2549

Vincent, J. B. 2015. Is the pharmacological mode of action of chromium (III) as a second messenger? Biol. Trace Elem. Res. 166:7-12.

Waggoner, J. W., C. A. Loest, J. L. Turner, C. P. Mathis, and D. M. Hallford. 2009. Effects of dietary protein and bacterial lipopolysaccharide infusion on nitrogen metabolism and hormonal responses of growing beef steers. J. Anim. Sci. 87:3656-3668.

Waldron, M. R., B. J. Nishida, R. L. Horst, and T. R. Overton. 2003a. Effect of lipopolysaccharide infusion on serum macromineral and vitamin D concentration in dairy cows. J. Dairy Sci. 86:3440-3446.

Waldron, M. R., T. Nishida, B. J. Nonnecke, and T. R. Overton. 2003b. Effect of lipopolysaccharide on indices of peripheral and hepatic metabolism in lactating cows. J. Dairy Sci. 86:3447-3459.

Walrand, S., C. Guillet, Y. Boirie, and M.-P. Vasson. 2004. In vivo evidence that insulin regulated human polymorphonuclear neutrophil functions. J. Leukoc. Biol. 76:1104-1110.

Yasui, T., J. A. A. McArt, C. M. Ryan, R. O. Gilbert, D. V. Nydam, F. Valdez, K. E. Griswold, and T. R. Overton. 2014. Effects of chromium propionate supplementation during the periparturient period and early lactation on metabolism, performance, and cytological endometritis in dairy cows. J. Dairy Sci. 97:6400-6410.

Yuan, K., C. F. Vargas-Rodriguez, L. K. Mamedova, M. B. Muckey, M. A. Vaughn, D. D. Burnett, J. M. Gonzalez, E. C. Titgemeyer, K. E. Griswold, and B. J. Bradford. 2014. Effects of supplemental chromium propionate and rumen-protected amino acids on nutrient metabolism, neutrophil activation, and adipocyte size in dairy cows during peak lactation. J. Dairy Sci. 97:3822-3831.

Zarrin, M., O. Wellnitz, H. A. van Dorland, J. J. Gross, and R. M. Bruckmaier. 2014. Hyperketonemia during lipopolysaccharide-induced mastitis affects systemic and local intramammary metabolism in dairy cows. J. Dairy Sci. 97:3531-3541.

Zhang, S., R. I. Albornoz, J. R. Aschenbach, D. R. Barreda, and G. B. Penner. 2013. Short-term feed restriction impairs the absorptive function of the reticulo-rumen and total tract barrier function in beef cattle. J. Anim. Sci. 91:1685-1695. 